\title{
Developing Therapeutics for Schizophrenia and Other Psychotic Disorders
}

\author{
Gerard Marek and Kalpana Merchant \\ Neuroscience Division, Eli Lilly and Company, Lilly Corporate Center, Indianapolis, Indiana 46285
}

\begin{abstract}
Summary: Although the second-generation or atypical antipsychotic drugs have been breakthrough medicines for the treatment of schizophrenia and other psychotic conditions, cognitive dysfunction and to some extent negative symptoms of the disease continue to be the main cause of poor vocational status of the patients. Thus, the majority of investigational drug development efforts today target these unmet medical needs. This review postulates that the field of schizophrenia research has advanced sufficiently to develop biochemical hypotheses of the etiopathology of the disease and target the same for revolutionary disease modifying therapy. This postulate is based on recent studies that have begun to provide a testable etiopathology model that integrates interactions between genetic vulnerability factors, neurodevelopmental anomalies, and neurotransmitter systems. This review begins with a brief overview of the nosology and etiopathology of schizophrenia and related psy-
\end{abstract}

chotic disorders to establish a context for subsequent detailed discussions on drug discovery and development for psychotic disorders. Particular emphasis is placed on recent advances in genetic association studies of schizophrenia and how this can be integrated with evidence supporting neurodevelopmental abnormalities associated with the disease to generate a testable model of the disease etiopathology. An in-depth review of the plethora of new targets and approaches targeting the unmet medical need in the treatment of schizophrenia exemplify the challenges and opportunities in this area. We end the review by offering an approach based on emerging genetic, clinical, and neurobiological studies to discover and validate novel drug targets that could be classified as disease modifying approaches. Key Words: Genetic etiopathology, neurodevelopmental etiology, investigational drugs, animal models, neurotransmission, neuroimaging, proof of concept clinical studies.

\section{INTRODUCTION}

Schizophrenia is a debilitating illness that affects up to $1 \%$ of the population around the world. Despite aggressive efforts to decrease hospital stays by managed care in the U.S., this psychiatric syndrome accounts for a disproportionate burden upon medical resources, including hospitalizations. Although treatments for the most obvious psychotic delusions and hallucinations have been available for over 50 years, little change in the vocational status of schizophrenic patients has occurred. This appears to be due to a pervasive cognitive dysfunction for which pharmacological agents have minimal impact. Among investigators in this field, a growing appreciation has emerged for an etiological neurodevelopmental hypothesis for schizophrenia in step with the rapidly advancing neurobiology underlying this clinical syndrome. Thus, a central question facing the psychopharmacolog-

Address correspondence and reprint requests to Kalpana Merchant, Neuroscience Division, Eli Lilly and Company, Lilly Corporate Center, Indianapolis, IN 46285. E-mail: merchantkm@lilly.com. ical advancements for this disorder is the degree to which symptomatic treatments can make further inroads on remaining negative symptoms and cognitive dysfunction. Recent breakthroughs in genetic studies of schizophrenia offer, for the first time, a hypothesis-driven approach for development of disease-modifying therapy for this debilitating disorder. This review is focused on providing a brief background on the nosology and etiopathology of schizophrenia and other psychotic disorders as well as a historical summary of available therapeutic agents. After setting this context, we will discuss new approaches for drug discovery and development of drugs that target the unmet medical need in the field.

\section{NOSOLOGY}

Schizophrenia is the most frequent and debilitating of the psychotic disorders. The psychotic disorders are characterized by a loss of contact with reality where patients have beliefs or perceptual experiences not shared by other members of their culture (delusions and hallucinations, respectively) or they engage in bizarre 
behavior. These symptoms comprise the so-called positive symptoms or psychotic domain of schizophrenia. Negative symptoms of blunted affect, anhedonia, apathy, and a reduced quantity or content of speech (alogia) are a second symptom domain in schizophrenia. These symptoms may be ameliorated partially (or at least not exaggerated) by second-generation antipsychotic (SGA) drugs, which tend to have a higher potency at the $5-\mathrm{HT}_{2 \mathrm{~A}}$ than dopamine $\mathrm{D} 2$ receptors. The third symptom domain involves cognitive impairment evident in the population of schizophrenic patients with problems in attention, learning, and memory, and a variety of executive functions (e.g., abstract thinking, problem solving, response inhibition). A cardinal feature of schizophrenia emphasized historically by Bleuler is disorganized thinking (e.g., loose associations) that is a dimension ranging from derailment (e.g., loose associations where the subjects moves from one topic to another largely out of context) to tangential thinking (where answers to questions are only indirectly related to the question) to especially severe dysfunction of incoherence or a word salad (the patients' speech or writing shows no obvious connections to objective observers). These "loosening of associations" have been redefined over the last 10 years as a "misconnection syndrome" or cognitive dysmetria due to dysfunction of cortico-cerebellar-thalamic-cortical circuits (CCTCC). ${ }^{1}$ The cognitive deficits associated with schizophrenia have been relatively unimproved by currently approved antipsychotic drugs, although there is some evidence for the superiority of second-generation antipsychotic drugs such as olanzapine and risperidone over first-generation antipsychotics. ${ }^{2-4}$ Unfortunately, this symptom domain appears to be most responsible for the poor vocational status of schizophrenic patients. ${ }^{5,6}$ Thus, cognitive impairment has been targeted by a joint academic, industry, and National Institute of Mental Health (NIMH) initiative termed MATRICS (Measurement and Treatment Research to Improve Cognition in Schizophrenia), which in turn has spawned a corresponding treatment initiative, TURNS (Treatment Units for Research on Neurocognition and Schizophrenia). ${ }^{7}$

Schizoaffective disorder is a relatively closely related clinical syndrome in which a mood disturbance is present concurrent with the active phase of schizophrenic symptoms, and the delusions or hallucinations are also present for at least 2 weeks in the absence of prominent affective symptoms. The diagnosis of schizophrenia also requires the presence of symptoms meeting full diagnostic criteria for at least 1 month (including a prodromal syndrome). If this duration is not met or functional impairment is not observed, the symptoms are classified as a schizophreniform disorder. Delusional disorder differs from schizophrenia primarily in that the age of onset is typically in the fifth to sixth decade of life ( $v s$ onset of the first break in the second to fourth decade) and symptoms are largely limited to paranoid delusions without prominent disorganized speech, bizarre behavior, flat or inappropriate affect. Patients with delusional disorder also present with a history of relatively good premorbid function. A substantial problem in the differential diagnosis of psychosis often is between a manic or mixed episode of bipolar disorder versus schizophrenia where the initial presentation to an emergency room physician can be quite similar, and primary clues to the correct diagnosis depend on a careful premorbid history, family psychiatric history, and the treatment response of the patient to mood-stabilizing drugs. ${ }^{8}$ Mood disorder with psychotic features (or psychotic depression) is characterized by delusions with depressive themes. Psychosis can be secondary also to medical conditions (e.g., untreated hypothyroidism, steroid treatment) or drugs of abuse. The long-lasting psychotic symptoms that are sometimes seen subsequent to hashish or marijuana, phencyclidine or ketamine, or hallucinogen (LSD, mescaline) use may reflect symptom exacerbation in individuals with an underlying disease vulnerability. The focus of this chapter will be on schizophrenia, although with pertinent discussion of bipolar disorder, given some of the genetic and pathophysiological overlap between these two major psychiatric syndromes.

\section{ETIOPATHOLOGY}

\section{Genetic epidemiology}

Evidence from family, twin, and adoption studies clearly indicates that genetic susceptibility plays a key role in the etiology of schizophrenia. ${ }^{9-11}$ These studies have led to the conclusions that the heritability for schizophrenia liability is around $80 \%,{ }^{12}$ and have provided the strongest rationale for continued molecular genetic studies as well as a search for common environmental factors contributing to the etiology of this disease. However, there do not appear to be Mendelian (monogenic) forms of the disease. Rather, it is now well accepted that multiple susceptibility genes, each of small effect, may act in concert with environmental factors to cause the disease. ${ }^{13}$ The high concordance rate of schizophrenia in monozygotic twins, and significantly reduced relative risk for the disease in distant relatives of schizophrenia probands, have led to the hypothesis that etiopathology of schizophrenia may involve fewer than 10 genes. ${ }^{14,15}$ Recent progress in genetic studies has led to identification of several replicated linkages and gene variants associated with the disease ${ }^{16,17}$ that may justify cautious classification of the susceptibility genes as "schizophrenia genes" (see Molecular Genetics of Schizophrenia). In addition, molecular linkage studies also suggest that schizophrenia and bipolar disorder share some of the genetic susceptibility. ${ }^{18}$ Multiple genomic loci represent areas of shared genetic suscepti- 
bility between schizophrenia and bipolar disorder. Taken together with common epidemiological characteristics of these diseases and recent evidence that olanzapine, an atypical, second-generation antipsychotic, reduces recurrence rates of depression as well as mania ${ }^{19}$ in bipolar patients indicates the nosology of the disorders may have to be modified in the near future on the basis of genetic findings and treatment responsiveness. Schizoaffective disorder and other schizophrenia spectrum disorders are more prevalent among families of probands with schizophrenia suggesting shared genetic etiology. However, sufficient replicated data are not available to conclude whether and which genetic susceptibility factors are shared by these psychotic disorders with schizophrenia.

\section{Neurodevelopmental disorder}

The most prevalent hypothesis for the pathogenesis of schizophrenia posits that the disease is a neurodevelopmental disorder associated with abnormal connectivity resulting from defects in synaptic synaptic pruning and migration of neurons..$^{20,21}$ There are a plethora of anatomical findings such as cortical cytoarchitectural abnormalities that would implicate events in the second trimester of gestation. A number of other early brain developmental abnormalities are seen with a higher frequency in schizophrenic patients such as aqueductal stenosis, arachnoid and septal cysts, agenesis of the corpus callosum, and reversal of normal structural cerebral asymmetries. ${ }^{22}$ When looking back at schizophrenic patients compared with normal probands or in prospective assessments of healthy adolescents, cognitive impairment, subtle motor dysfunction, and poor school performance often are evident before the first psychotic break or an obvious prodromal stage. ${ }^{23-25}$ These early, premorbid characteristics of schizophrenic patients combined with structural brain changes observed in first-episode neuroleptic-naïve patients are consistent with a neurodevelopmental pathophysiology for schizophrenia. ${ }^{26-32} \mathrm{An}$ example of cellular evidence for neurodevelopmental defects in schizophrenia is present in the altered distribution of interstitial neurons in the white matter underlying the prefrontal cortex reflecting either abnormalities in migration of subplate neurons or programmed cell death. ${ }^{33}$ These premorbid neuropsychological and neuroanatomical changes combined with the usual onset of schizophrenia between the ages of 16 and 30 are consistent with the knowledge that a number of developmental tasks remain to be completed for the maturation of brain function (e.g., synaptic pruning) through the early third decade of life. ${ }^{34}$

The neuroanatomical changes in the prefrontal cortex and neocortex largely appear to be due to a pruning of the neuropil (synaptic space) rather than a change in the number of neurons. Modern stereological methods have found an abnormally high neuronal density in the schizo- phrenic prefrontal and neocortex. ${ }^{35}$ These changes in the schizophrenic brain appear different from those observed in bipolar disorder where there is a decreased neuronal and glial density associated with glial hypertrophy. ${ }^{36}$ At the level of individual cell types, the basilar dendritic area surrounding the principal cortical output cell, the layer $\mathrm{V}$ pyramidal neuron, is decreased in schizophrenia. ${ }^{37}$ A decreased spine density on deep layer 3 pyramidal neurons, unlike superficial layer 3 pyramidal neurons, was observed in the prefrontal cortex of schizophrenic patients. ${ }^{38}$ These observations with layer 3 pyramidal cells are consistent with a decreased thalamic input from the mediodorsal thalamic nucleus (see below) and/or decreases in cortical afferents. Further detail in the cortical microcircuitry has revealed that a special type of GABAergic interneuron, the chandelier cell (one of 20 or more types of cortical interneurons), each of which projects to the initial axon segments of the pyramidal cells, appear to provide a compromised inhibitory regulation over ensembles of cortical output cells. ${ }^{39}$ These findings may be relevant to the observations from functional imaging studies showing that not only do schizophrenic patients have a hypofunction of prefrontal regions, but that there is an abnormal recruitment of cortical activity during different cognitive tasks. ${ }^{40}$

The thalamus, a structure with multiple channels of thalamocortical and corticothalamic connections in addition to providing afferents to the amygdala, the striatum and subiculum, increasingly is being implicated in the pathophysiology of schizophrenia. ${ }^{41}$ Beginning with Andreasen and colleagues, ${ }^{42}$ about half of the magnetic resonance imaging (MRI) reports have found a reduced thalamic volume, which may be restricted to nuclei such as the dorsomedial, pulvinar, central medial, anterior and posteromedial thalamic nuclei. Five of six different groups using postmortem studies stereological studies have found a decreased number of mediodorsal thalamic neurons, especially in those regions projecting to the dorsal and lateral prefrontal cortex, the striatum and premotor cortical regions. Some of the studies have also suggested cell loss in the pulvinar, the anteroventral/ anteromedial thalamic, and the ventral lateral posterior nuclei. Consistent with these findings, positron emission tomography studies examining subjects performing cognitive tasks reported reduced thalamic metabolic rates.

The medial temporal lobe is a region of the brain that appears to be differentially involved in schizophrenia as compared with bipolar disorder. ${ }^{8}$ The amygdala appears to be decreased in size for schizophrenic patients compared with control patients, ${ }^{43,44}$ and certainly so for schizophrenic patients compared with bipolar patients. ${ }^{45}$ Changes in neuronal or glial density, however, have not been reported. Evidence has also accumulated that all portions of the hippocampal formation (subiculum, parahippocampal gyrus, and entorhinal cortex) are involved 
in schizophrenia. ${ }^{8,44,46}$ There also has been evidence for either abnormally placed neurons in the entorhinal cortex or disarray of pyramidal neurons at the boundaries of the hippocampal field CA1 with CA2 and the subiculum. A clinical context for these findings are the repeated association of schizophrenia with obstetrical complications with preeclampsia (an indicator of fetal malnutrition) high on the list of neuropathological insults. ${ }^{47}$

Consistent changes in the neostriatum of schizophrenic patients with no or minimal antipsychotic drug treatment have not been seen. However, an increased striatal volume does appear in patients treated with first-generation or typical antipsychotic drugs. ${ }^{48}$ There is also some evidence that striatal volume tends to return to normal when a secondgeneration antipsychotic drug is substituted for a first-generation typical antipsychotic drug. ${ }^{49,50}$

From a functional standpoint, hypotheses of dopaminergic hyperactivity have been prominent in the field of schizophrenia. A recent series of neuroimaging studies from Laruelle, Abi-Dargham, and colleagues ${ }^{51-54}$ have suggested that schizophrenia is characterized by an enhanced amphetamine-induced dopamine release during the initial onset and in patients previously not exposed to antipsychotic drugs.

Cerebellar abnormalities also have been noted in schizophrenia. Functional magnetic resonance spectroscopy has found reduced cerebellar $\mathrm{N}$-acetylasparate in schizophrenic patients. ${ }^{55,56}$ An MRI study reported increased volume of the vermis and greater vermis white matter volume from a cohort of schizophrenic patients compared with normal subjects. ${ }^{57}$

\section{MOLECULAR GENETICS OF SCHIZOPHRENIA}

\section{Positional cloning and candidate gene association studies}

The high heritability of schizophrenia has spawned a number of linkage studies. Despite the failure to replicate all linkages, sufficient data have emerged and recent meta-analyse ${ }^{58,59}$ have identified linkages at the following loci: 8p, 22q, 2q, 3p, 6p, 1q, 11q, 5q, 13q, and 20p. This led to application of modern molecular genetic studies to identify single nucleotide polymorphisms (SNPs) within the linked loci, establish the association of the SNPs with schizophrenia and identify candidate genes containing the SNPs (i.e., the classical positional cloning approach). This path has led to the breakthrough identification of several schizophrenia susceptibility genes. Thus neuregulin $1,{ }^{60,61}$ dysbindin, ${ }^{62,63} \mathrm{G} 72,{ }^{64}$ deaminoacid oxidase, regulator of $\mathrm{G}$ protein signaling- $4,{ }^{65,66}$ catechol-O-methytransferase (COMT), ${ }^{67,68}$ and proline dehydrogenase $^{69}$ represent results of the molecular genetic breakthroughs in schizophrenia research. Although the results are to be viewed with caution until further repli- cation is documented unequivocally, the association of these genes with schizophrenia offers an unprecedented opportunity to understand the pathogenesis and pathophysiology of this disease. In fact, Harrison and Owen ${ }^{16}$ have proposed a hypothetical construct of pathophysiology of the disease that involves convergent interactions among the seven genes listed above. This approach holds tremendous promise. For the first time, hypothesis-driven schizophrenia research is likely to lead to better therapeutic strategies, both by enabling better animal models and by potentially offering the ability to assess biochemical pathways associated with the disease pathophysiology.

In addition to these classical studies, several investigators have been performing genetic studies on endophenotypes of schizophrenia. These are intermediate phenotypes that segregate with the genetic risk for schizophrenia. ${ }^{70,71}$ The endophenotypes offer the advantage of using objective neurophysiological measures such as deficits in smooth-pursuit eye tracking, ${ }^{72-74}$ or suppression of auditory evoked potentials, such as the

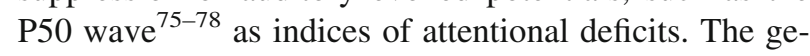
netics of schizophrenia-associated endophenotypes have begun to provide significant insights into biological processes contributing to disease susceptibility ${ }^{71}$ and have offered other candidate genes or loci. Thus, Arolt et al. ${ }^{79}$ reported a linkage of abnormal smooth-pursuit eye tracking with a locus on the short arm of chromosome 6 without identifying a gene or gene variants in the locus. Similarly, Freedman et al. ${ }^{80}$ linked the abnormal P50 wave to a locus on the long arm of chromosome 15 , which contains the nicotinic $\alpha 7$ gene, ${ }^{81}$ a drug target being pursued by several companies. It should be noted that some scientists question the relevance of genetic association with endophenotypes because deficits in eyetracking and abnormal evoked potentials are significantly more frequent in the general population than schizophrenia. ${ }^{82}$ Another promising research strategy uses molecular imaging to study interactions between genetic and environmental factors that contribute to intermediate phenotypes such as working memory deficits in schizophrenia. Thus, Weinberger and co-workers ${ }^{83}$ have been exploiting the advances in molecular genetic and noninvasive imaging technologies such as functional MRI to identify functional neural circuitry associated with genetic polymorphisms. These studies provide insights into disease-related neural circuits and their modulation by genetic susceptibility factors. This understanding is critical, in turn, for identification of druggable targets, generation of better animal models, and biomarkers for proof of concept studies.

\section{PHARMACOTHERAPY}

\section{First-generation or typical antipsychotics}

The modern era of pharmacological treatment for schizophrenia can be dated to the introduction of the 
phenothiazine, chlorpromazine, in 1952 by Delay and Deniker. ${ }^{84}$ Within a decade, Arvid Carlsson ${ }^{85}$ had suggested that both chlorpromazine and the butyrophenone haloperidol might act in schizophrenia by blocking brain dopamine receptors. The development of receptor binding techniques led to the discovery that the clinical potency of both phenothiazines and butyrophenones in treating psychotic behavior is related to blockade of dopamine D2 receptors, rather than dopamine D1 receptors. ${ }^{86,87}$ Thus, by the 1980s a number of antipsychotic drugs that shared potent dopamine D2 receptor blockade had been released, including the phenothiazines (chlorpromazine, triflupromazine, thioridazine, mesoridazine, trifluoperazine, perphenazine, fluphenazine), the thioxanthenes (chlorprohixene, thiothixene), the butyrophenones (haloperidol), a dibenzoxazepine (loxapine), and a dihydroindolone (molindone). Although this class of drugs worked effectively at treatment of positive psychotic symptoms, they induced dose-limiting extrapyramidal motor deficits as well as exacerbated negative symptoms and failed to affect cognitive deficits.

\section{Second-generation or atypical antipsychotic drugs (SGA)}

In an attempt to mitigate against the extrapyramidal side effects (EPS) that range from Parkinsonian symptoms to tardive dyskinesia, an effort to build in more potent $5-\mathrm{HT}_{2 \mathrm{~A}}$ receptor blockade was begun which led to the development of SGA drugs, also known as atypical antipsychotic drugs. Thus, since the introduction of chlorpromazine, well over 30 antipsychotic drugs have become available for the treatment of schizophrenia. ${ }^{88}$ Some of the SGAs such as clozapine, amisulpride, risperidone, and olanzapine have been found to produce greater effect sizes than the first-generation antipsychotic (FGAs) drugs on overall antipsychotic efficacy ${ }^{3}$ in addition to reduced EPS liability. This greater efficacy for SGAs compared with FGAs was not observed for all SGA class members in the relatively limited sample available (e.g., aripriprazole, sertindole, quetiapine, ziprasidone, and remoxipride). It remains to be seen whether a greater effect size will be seen with this latter group of SGAs as more studies become available. Consistent with reduced EPS load, the SGAs also have a reduced liability toward hyperprolactinemia. With regard to the SGAs, it should be noted that clozapine stands out with respect to efficacy in treatment-refractory patients and for patients at risk for suicide. ${ }^{89,90}$ The relatively infrequent agranulocytosis accompanying clozapine has greatly limited cloazapine usage. An additional drawback associated with clozapine is sedation.

\section{Dopamine D2 partial agonists}

Thus far, only one dopamine D2 partial agonist has been approved by regulatory agencies for the acute treatment of schizophrenia, aripiprazole. ${ }^{91}$ Aripiprazole is a potent partial agonist at dopamine $\mathrm{D} 2$ and $5-\mathrm{HT}_{1 \mathrm{~A}}$ receptors and an antagonist at $5-\mathrm{HT}_{2 \mathrm{~A}}$ receptors among other less potent pharmacological actions. ${ }^{92}$ This atypical antipsychotic appears to have a reduced liability toward weight gain, but it is not yet known if this factor will also translate into a decreased liability for schizophrenic patients to develop type 2 diabetes mellitus. A number of other dopamine D2 partial agonists (e.g., talipexole, roxindole, and SDZ HDC 912) also have been in clinical development, though they either were not as effective as the current standard of care or they did not have sustained action at therapeutic doses. ${ }^{93,94}$

\section{Other major investigational approaches}

Modulation of NMDA receptor neurotransmission. One of the most frequently studied approaches to improving cognitive function and reducing negative symptoms of schizophrenic patients is enhancing NMDA receptor function by acting on the glycine modulatory site (GMS). ${ }^{95,96}$ A recent review of a series of relatively small placebo-controlled studies have suggested that either high-dose glycine, D-serine, or the partial agonist D-cycloserine improve negative symptoms, cognitive dysfunction, and depression when added to antipsychotic drugs other than clozapine. ${ }^{97}$ In contrast, either symptom exacerbation or lack of symptomatic improvement has been observed with agonists or partial agonists when the GMS are added to ongoing treatment with clozapine. A recent meta-analysis of glutamatergic drugs (e.g., glycine, D-serine, D-cycloserine, and the AMPAkine CX516) added to antipsychotic drug treatment found a moderate effect size for glycine or D-serine added to antipsychotics with respect to negative symptoms. ${ }^{98}$ Only a trend was present for cognitive dysfunction. Little evidence for a beneficial effect was found with D-cycloserine augmentation. A recent study of adjunctive D-cycloserine in patients predominantly with negative symptoms failed to demonstrate efficacy ${ }^{99}$ It should also be noted that a relatively large multicenter, double-blind, placebo-controlled study of D-cycloserine and glycine drugs failed to observe symptomatic improvement for negative or cognitive symptoms. ${ }^{100}$

Serotonin 5-HT $\mathbf{T}_{\mathbf{2 A}}$ antagonists. One example of an extensively explored approach for selectively targeting a single receptor thought to play a key role in pathophysiology of schizophrenia is the investigation of selective $5-\mathrm{HT}_{2 \mathrm{~A}}$ receptor antagonists as putative antipsychotic drugs. The development of the highly selective $5-\mathrm{HT}_{2 \mathrm{~A}}$ receptor antagonist, M100907, ${ }^{101}$ was discontinued after two phase 3 studies in the U.S. found M100907, although superior to placebo, to be inferior to haloperidol and a European phase 3 study in schizophrenic patients with predominant negative symptoms failed to observe separation of the M100907 from placebo. ${ }^{102}$ The termination decision was derived in large part from objective recep- 
tor occupancy studies in healthy humans that confirmed that M100907 was tested at doses that saturate prefrontal cortical $5-\mathrm{HT}_{2 \mathrm{~A}}$ receptors. ${ }^{103}$ Furthermore, a phase 2 study of SR46349B (eplivanserin), another 5- $\mathrm{HT}_{2}$ receptor antagonist with approximately 20 -fold selectivity for $5-\mathrm{HT}_{2 \mathrm{~A}}$ over $5-\mathrm{HT}_{2 \mathrm{C}}$ receptors, also showed antipsychotic efficacy intermediate between that of placebo and haloperidol. ${ }^{104}$ An unresolved challenge is how a modestly effective therapeutic with a presumed superior side effect profile can be used in the clinic either as a monotherapy or in combination with other agents during different stages of the schizophrenia syndrome.

Neurokinin 3 NK3 receptor antagonist. Another mechanism of action that may be associated with a relatively modest degree of efficacy is blockade of neurokinin 3 (NK3) receptors. The same meta-trial that found modest efficacy for the Sanolfi-Aventis (Paris France) $5-\mathrm{HT}_{2}$ receptor antagonist also reported antipsychotic efficacy for the NK3 receptor antagonist, SR142801, that was intermediate between placebo and haloperidol. ${ }^{104}$ This NK3 receptor antagonist is reportedly in a phase $2 b$ trial. GlaxoSmithKline (UK, USA) also appears to have a NK3 receptor antagonist, talnetant (SB-223412), that undergoing phase $2 \mathrm{~b}$ testing (ClinicalTrials.gov identifier NCT00103727) involving both a placebo and an active comparator (risperidone).

Dopamine D4 receptor antagonist. Dopamine D4 antagonists appear to lack appreciable efficacy in the treatment of acute schizophrenia. A relatively small phase 2 study reported a slight worsening of patients relative to the placebo group following treatment with L-745,870. ${ }^{105}$ These results were confirmed in a recent, large multicenter, placebo- and active comparator (olanzapine)-controlled, study involving a 40-fold dose range for a Pfizer (USA) dopamine D4 receptor antagonist (sonepiprazole). ${ }^{106}$ Given these results, it is not surprising that a dopamine $\mathrm{D}_{4} / 5-\mathrm{HT}_{2 \mathrm{~A}} / \alpha-1$ adrenergic receptor antagonist also did not exhibit antipsychotic efficacy in a relatively small (97 patients with approximately $2: 1$ active:placebo randomization) phase 2 study in the treatment of schizophrenia patients. ${ }^{107}$

Neurotensin NTS1 antagonist. The placebo-controlled meta-trial using haloperidol as a positive comparator that demonstrated moderate efficacy for the SanolfiAventis NK3 receptor antagonist and 5- $\mathrm{HT}_{2}$ receptor antagonist failed to see any efficacy for a neurotensin NTS1 antagonist (SR48692).

Cannabinoid CB1 receptor antagonist. In the trial listed above, ${ }^{104}$ the cannabinoid-1 (CB1) receptor antagonist, SR141716 (rimonabant), at the dose (20 mg) efficacious at reducing weight showed no antipsychotic efficacy. This report did not disclose whether positive effects were seen for any of the treatments on cognitive dysfunction or whether there was an effect of rimonabant on weight. Regarding the relationship of $\mathrm{CB} 1$ receptors to psychosis, it is interesting to note that a recent report found patients abusing cannabis appeared to have a higher degree of psychopathology and longer duration of hospitalization in British psychiatric intensive care units. $^{108}$

Other miscellaneous targets. A number of additional investigational therapies are in progress at the present time. A small phase 2 study is underway for the $\alpha 7$ nicotinic agonist (3-2, 4 dimethoxy benylidene) for improving cognitive dysfunction in schizophrenia patients employing the MATRICS battery (ClinicalTrials.gov identifier NCT00100165). The NIMH is sponsoring a study examining whether pharmacogenomic status may be informative for the effects of the COMT inhibitor, tolcapone. Other investigational putative antipsychotic agents currently in phase 3 include bifeprunox (Wyeth \& Solvay Pharmaceuticals, USA; DU-127090, a partial agonist at dopamine $\mathrm{D} 2$ and $5-\mathrm{HT}_{1 \mathrm{~A}}$ receptors), paliperidone extended release (Johnson \& Johnson, an active risperidone metabolite), asenapine (Organon, Netherlands, USA; Pfizer; ORG 5222; a 5-HT2 antagonist/ dopamine D2 partial agonist). Other phase 2 investigational compounds include ORG 24448 (Organon, Cortex, USA; an AMPA potentiator), ACP-103 (Acadia, USA, a $5-\mathrm{HT}_{2 \mathrm{~A}}$ inverse agonist, ClinicalTrials.gov identifier NCT00087542), lonasen [blonanserin, Dainippon Pharmaceuticals, Japan] a D2/5- $\mathrm{HT}_{2 \mathrm{~A}}$ receptor antagonist), talnetant (the GlaxoSmithKline NK3 receptor antagonist discussed above, SB-223412), secretin (Repligen RG1068 endogenous pancreatic hormone for psychosis and autism).

\section{CHALLENGES OF DRUG DISCOVERY}

\section{Target identification and validation}

Until recently, new therapies emerged from the serendipitous discovery of chlorpromazine as an antipsychotic and a quest to discover new drugs that lack the extrapyramidal motor side effects of the older, so-called, typical antipsychotics. It is true that the atypical antipsychotics have provided a significant benefit to the patient via not only better therapeutic margin but also somewhat better efficacy at treating the negative symptoms of schizophrenia. However, future drug discovery approaches have to be truly revolutionary, and this will require target identification and validation methods based on a better understanding of the pathogenesis of the disease. Clearly, an understanding of the genetic etiology of the disease is critical to be able to identify new targets in a pathogenic biochemical pathway. In fact, the success of the disease modifying therapy approaches for Alzheimer's disease is a testament to the ability to convert genetic breakthroughs into druggable approaches. Thus, the identification of familial mutations in amyloid precursor protein and presenilins in a small fraction of patients led to the 
identification of a pathogenic biochemical pathway regulating A- $\beta$ production or clearance and thereby identification of $\beta$ and $\gamma$ secretases as drug discovery targets (although none have reached registration status today). However, two factors are likely to hamper a similar breakthrough in schizophrenia research: 1) lack of a stable, objective phenotype associated with the disease pathophysiology (e.g., A- $\beta$ deposition in Alzheimer's disease) and 2) absence of the Mendelian form of the disease. Nonetheless, the success of the recent molecular genetic studies suggests that a better understanding of the etiopathology of schizophrenia will likely be achieved in the recent future.

\section{Limitations of animal models}

The most commonly used animal models for antipsychotic drug discovery are based on pharmacological manipulation (typically psychostimulant-induced behaviors). These models traditionally have helped identify antagonists at dopamine $\mathrm{D}_{2}$ or serotonin $5-\mathrm{HT}_{2 \mathrm{~A}}$ receptors, core pharmacological activity of FGA and SGA, respectively. A number of models are founded also on the neurodevelopmental hypothesis of schizophrenia. ${ }^{109,110}$

Of these, the neonatal hippocampal lesioned rat represents a widely used model and is characterized extensively by Lipska et al. ${ }^{111}$ However, this model, too, suffers from poor construct validity to be applied for new target discovery. Additionally, it is highly labor intensive and does not lend itself readily to drug screening. The end-points applied to these animal models vary from locomotor activity to pre-pulse inhibition of the startle response, the latter reflecting sensory gating deficits associated with schizophrenia. ${ }^{112}$ However, the clinical translation of these end-points, with the exception of the pre-pulse inhibition, is poor. Thus, the biggest limitation for target identification and validation for novel drug therapies targeting unmet medical needs or disease modification is the lack of a disease etiology or pathologybased animal model. This is especially true for models of negative symptoms because in rodents these have to rely on anthropomorphized and nonspecific outcome measures such as social behaviors between rodents. The vast literature on animal constructs of cognitive behaviors have led generally to the expectation that models of cognitive deficits of schizophrenia should be relatively easier to simulate in rodent and nonhuman primates, thereby facilitating discovery of procognitive drugs. However, a number of animal tests have poor translatability to the clinical constructs, are not specific to a disease, have a small dynamic range, and are too complex to be reliably replicated between laboratories. Additionally, few have the requisite throughput for screening novel drug candidates. Thus, overall the progress for novel therapeutics for schizophrenia has been severely

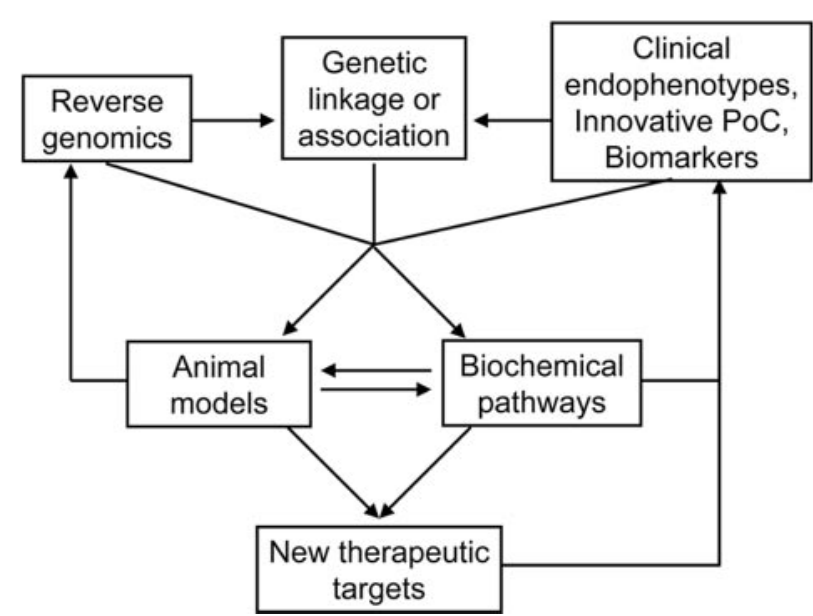

FIG. 1. A schematic diagram depicts a drug discovery and development approach based on emerging understanding of schizophrenia etiopathology.

hampered by the lack of predictive, reliable, and efficient animal models.

\section{Clinical proof of concept studies}

At a clinical level, cognitive dysfunction remains one of the most challenging areas for developing antipsychotic drugs. For the near term and given our poor understanding of the etiology of schizophrenia, it would appear unlikely that a single treatment would target psychotic, negative, and cognitive symptoms. The more likely path toward success would be the development of novel drugs, that when added to SGAs, would result in significant cognitive improvement. A recent review from the MATRICS initiative described seven cognitive domains (working memory, attention/vigilance, verbal learning and memory, visual learning and memory, reasoning and problem solving, information processing speed, and social cognition) that should be targeted by a cognitive test battery. ${ }^{113}$ Keefe and colleagues ${ }^{114}$ have recently described a newly developed instrument, the Brief Assessment of Cognition in Schizophrenia, which appears to meet a number of criteria for a practical, reliable test with construct validity. It remains to be seen how well this instrument will predict outcome for SGAs or novel therapeutic agents.

\section{EMERGING OPPORTUNITIES FOR DRUG DISCOVERY AND DEVELOPMENT}

Figure 1 schematically represents an approach of antipsychotic drug discovery and development that utilizes emerging understanding of the disease pathophysiology from genetic, genomic, and clinical research. As discussed above and depicted in the figure, these studies have led to and in the near future could provide further 
refined, testable hypothesis for the biochemical pathways associated with the disease etiology and/or progression. Two emerging areas most likely to be affected by these new discoveries as well as most critically needed to revolutionize antipsychotic drug development are animal models and clinical proof of concept studies as discussed below.

\section{Genetic etiology-based animal models}

Generation of genetic etiology-based rodent models (e.g., neuregulin knockout) and their careful phenotypic characterization by a combination of behavioral, physiological, and functional neuroanatomical end-points chosen on the basis of clinical studies of schizophrenic patients will help establish a model with construct and face validity to facilitate novel target validation and drug screening. In choosing the end-points, it would be critical to include those with a reasonable clinical counterpart (e.g., pre-pulse inhibition for sensory gating deficits). Additionally, such models may be used to identify new targets by the application of global, unbiased techniques such as gene chip microarrays to identify target pathways associated with genetic vulnerability factors. Here again, the field is ripe to take advantage of the recent advances in the technology and its successful application to studies of genomic alterations in postmortem schizophrenic brains ${ }^{115,116}$ to assess or establish the validity of the various animal models. Finally, the validated animal models are critically needed to discover biomarkers of disease progression. Applying lessons from progressive neurological disease such as Alzheimer's disease, it may be possible, some day, to use the animal model(s) to identify a biochemical marker in the CSF that correlates with the disease phenotype. A targeted or unbiased proteomic and/or metabonomics approach may yield valuable information on disease-associated biochemical alterations in an accessible, relevant compartment.

\section{Clinical proof of concept studies-endophenotypes and pharmacogenomics}

The heterogeneity of schizophrenia raises serious question as to whether simply identifying endophenotypes for schizophrenia (e.g., neuropsychological instruments, pursuit eye movements, P50 auditory event-related potentials) will be a sufficient strategy to lead to therapeutic breakthroughs. ${ }^{117} \mathrm{~A}$ recent example involving a functional polymorphism [Val (108/158)Met] in the COMT gene addresses how genomic stratification may provide links to prefrontal physiology, cognitive function, and clinical improvement. ${ }^{118}$ A successful study in a genomically stratified population would lead to further widespread clinical phase 2 testing using genotyping strategies along with functional imaging to confirm and extend the initial proof of concept study.

\section{CONCLUSIONS}

In conclusion, the second-generation antipsychotic drugs represent a significant advance in the psychotherapeutics of schizophrenia. However, a major focus for future drug discovery and development efforts is on the unmet medical need of cognitive deficits and disease modification. Several recent advances in the field indicate that the latter objective may be attainable in the not too distant a future; some of the key advances include 1) identification of replicated genetic susceptibility factors; 2) better understanding of endophenotype-genotype correlations; and 3) accumulated experience in the use of unbiased techniques to assess changes in disease-associated transcriptome, proteome, and metabolome. Additionally, application of learnings from the successful and failed clinical trials to refine the disease model is critical to ensure success of future efforts. An area that needs further improvement to facilitate target and drug discovery is the development of animal models based on etiopathology and using clinically translatable end-points.

Acknowledgments: The authors thank Drs. Kjell Svensson and Kurt Rasmussen for critical reading of the review.

\section{REFERENCES}

1. Andreasen NC. A unitary model of schizophrenia. Bleuler's "Fragmented Phrene" as schizencephaly. Arch Gen Psychiatry 56:781-787, 1999.

2. Bilder RM, Goldman RS, Volavka J, Czobor P, Hoptman M, B. Sheitman, Lindenmayer J-P, Citrome L, McEvoy J, Kunz M, Chakos M, Cooper TB, Horowitz TL, Lieberman JA. Neurocognitive effects of clozapine, olanzapine, risperidone, and haloperidol in patients with chronic schizophrenia or schizoaffective disorder. Am J Psychiatry 159:1018-1028, 2002.

3. Davis JM, Chen N, Glick ID. A meta-analysis of the efficacy of second-generation antipsychotics. Arch Gen Psychiatry 60:553564, 2003.

4. Harvey PD, Keefe RSE. Studies of cognitive change with treatment in schizophrenia. Am J Psychiatry 158:176-184, 2001.

5. Green MF. What are the functional consequences of neurocognitive deficits in schizophrenia? Am J Psychiatry 153:321-330, 1996.

6. Green MF, Kern RS, Braff DL, Mintz J. Neurocognitive deficits and functional outcome in schizophrenia: are we measuring the "right stuff." Schizophr Bull 26:119-136, 2000.

7. Geyer MA, Tamminga CA. Measurement and treatment research to improve cognition in schizophrenia: neuropharmacological aspects. Psychopharmacology 174:1-2, 2004.

8. Murray RM, Sham P, Van Os J, Zanelli J, Cannon M, McDonald C. A developmental model for similarities and dissimilarities between schizophrenia and bipolar disorder. Schizophr Res 71: 405-416, 2004.

9. Kety SS. Schizophrenic illness in the families of schizophrenic adoptees. Schizophr Bull 14:217-222, 1988.

10. Tsuang MT, Gilbertson MW, Faraone SV. The genetics of schziophrenia. Current knowledge and future directions. Schizophr Res 4:157-171, 1991.

11. Kendler KS. Overview: a current perspective on twin studies of schizophrenia. Am J Psychiatry 140:1413-1425, 1983.

12. Owen MJ, O’Donovan M, Gottesman II. Schizophrenia. Psychiatric genetics and genomics (McGuffin P, Owen MJ, Gottesman II, eds) pp 247-266. London: Oxford University Press, 2002. 
13. Moldin SO. Report of the National Institute of Mental Health's Genetic Workgroup. Summary of Research. Biol Psychiatry 45: 573-602, 1999.

14. Faraone SV, Tsuang MT. Quantitative models of the genetic transmission of schizophrenia. Psychol Bull 98:41-66, 1985

15. Risch N. Genetic linkage and complex diseases, with special reference to psychiatric disorders. Genet Epidemiol 7:3-16, 1990.

16. Harrison PJ, Owen MJ. Genes for schizophrenia? Recent findings and pathophysiological implications. Lancet 361:417-419, 2003.

17. Ban TA. Neuropscyhopharmacology and the genetics of schizophrenia - a history of the diagnosis of schizophrenia. Prog Neuropsychopharmacol Biol Psychiatry 28:753-762, 2004.

18. Barettini W. Evidence of shared susceptibility in bipolar disorder and schizophrenia. Am J Med Genet 123C:59-64, 2003.

19. Tohen M, Ketter TA, Zarate CA, Suppes T, Frye M, Altschuler L, et al. Olanzapine versus divalproex sodium for the treatment of acute mania and maintenance of remission: a 47-week study. Am J Psychiatry 160:1263-1271, 2003.

20. Weinberger DR. Implications of normal brain development for the pathogenesis of schizophrenia. Arch Gen Psychiatry 44:660 669, 1987.

21. Lewis DA, Levitt P. Schizophrenia as a disorder of neurodevelopment. Annu Rev Neurosci 25:409-432, 2002.

22. Mueser KT, McGurk SR. Schizophrenia. Lancet 363:2063-2072, 2004.

23. Amminger GP, Pape S, Rock D, Roberts SA, Ott SL, SquiresWheeler E, Kestenbaum C, Erlenmeyer-Kimling L. Relationship between childhood behavioral disturbance and later schizophrenia in the New York High-Risk Project. Am J Psychiatry 156: 525-530, 1999.

24. Davidson M, Reichenberg A, Rabinowitz J, Weiser M, Kaplan Z, Mark M. Cognitive and behavioral markers for schizophrenia in apparently healthy adolescents. Am J Psychiatry 156:1328-1335, 1999.

25. Walker E, Lewine RJ. Prediction of adult-onset schizophrenia from childhood home movies of the patients. Am J Psychiatry 147:1052-1056, 1990.

26. DeLisi LE, Hoff AL, Schwartz JE, Schields GW, Halthore SN, Gupta SM, Henn FA, Anand AK. Brain morphology in firstepisode schizophrenic-like psychotic patients: a quantitative magnetic resonance imaging study. Biol Psychiatry 29:159-175, 1991.

27. Gur RE, Maany V, Mozley PD, Swanson C, Bilker W, Gur RC. Subcortical MRI volumes in neuroleptic-naive and treated patients with schizophrenia. Am J Psychiatry 155:1711-1717, 1998.

28. Lieberman JA, Bogerts B, Degreef G, Ashtari M, Lantos G, Alvir J. Qualitative assessment of brain morphology in acute and chronic schizophrenia. Am J Psychiatry 149:784, 1992.

29. Lieberman JA, Jody D, Alvir JM, Ashtari M, Levy DL, Bogerts B, Degreef G, Mayerhoff I, Cooper T. Brain morphology, dopamine, and eye-tracking abnormalities in first-episode schizophrenia. Prevalence and clinical correlates. Arch Gen Psychiatry 50: 357-368, 1993.

30. Lim KO, Tew W, Kushner M, Chow K, Matsumoto B, DeLisi LE. Cortical gray matter volume deficit in patients with firstepisode schizophrenia. Am J Psychiatry 153:1548-1553, 1996.

31. Nopoulos P, Torres I, Flaum M. Brain morphology in first episode schizophrenia. Am J Psychiatry 152:1721-1723, 1995.

32. Zipursky R, Lambe EK, Kapur S, Mikulis DJ. Cerebral gray matter volume deficits in first episode psychosis. Arch Gen Psychiatry 55:540-546, 1998.

33. Akbarian S, Kim JJ, Potkin SG, Hetrick WP, Bunney WEJ, Jones EG. Maldistribution of interstitial neurons in prefrontal white matter of the brains of schizophrenic patients. Arch Gen Psychiatry 53:425-436, 1996.

34. Lewis DA. Development of the prefrontal cortex during adolescence: insights into vulverable neural circuits in schizohrenia. Neuropychopharmacology 16:385-398, 1997.

35. Selemon LD, Rajkowska G, Goldman-Rakic PS. Abnormally high neuronal density in the schizophrenic cortex. Arch Gen Psychiatry 52:805-818, 1995.

36. Rajkowska G, Harlaris A, Selemon LD. Reductions in neuronal and glia density characterize the dorsolateral prefrontal cortex in bipolar disorder. Biol Psychiatry 49:741-752, 2001.

37. Black JE, Kodish IA, Grossman AW, Klintsova AY, Orlovskaya D, Vostrikov V, Uranova N, Greenough WT. Pathology of layer $\mathrm{V}$ pyramidal neurons in the prefrontal cortex of patients with schizophrenia. Am J Psychiatry 161:742-744, 2004.

38. Glantz LA, Lewis DA. Decreased dendritic spine density on prefrontal cortical pyramidal neurons in schizophrenia. Arch Gen Psychiatry 57:65-73, 2000.

39. Lewis DA, Volk DW, Hashimoto T. Selective alterations in prefrontal cortical GABA transmission in schizophrenia: a novel target for the treatment of working memory dysfunction. Psychopharmacology 2004:143-150, 2004.

40. Weinberger DR, Berman KF. Prefrontal function in schizophrenia: confounds and controversies. Phil Trans Royal Soc London Series B: Biol Sci 351:1495-1503, 1996.

41. Clinton SM, Meador-Woodruff JH. Thalamic dysfunction in schizophrenia: neurochemical, neuropathological, and in vivo imaging abnormalities. Schizophrenia Res 69:237-253, 2004.

42. Andreasen NC, Arndt S, Swayze IIV, Cizadlo T, Flaum M, O'Leary D, Ehrhardt JC, Yuh WTC. Thalamic abnormalities in schizophrenia visualized through magnetic resonance averaging. Science 266:294-298, 1994.

43. Strakowski SM, DelBello MP, Sax KW, Zimmerman ME, Shear PK, Hawkins JM, Larson ER. Brain magnetic resonance imaging of structural abnormalities in bipolar disorder. Arch Gen Psychiatry 56:254-260, 1999.

44. Wright IC, Rabe-Hesketh S, Woodruff PWR, David AS, Murray RM, Bullmore ET. Meta-analysis of regional brain volumes in schizophrenia. Am J Psychiatry 157:16-25, 2000.

45. Altshuler LL, Bartzokis G, Grieder T, Curran J, Mintz J. Amygdala enlargement in bipolar disorder and hippocampal reduction in schizophrenia: an MRI study demonstrating neuroanatomic specificity. Arch Gen Psychiatry 55:663-664, 1998.

46. Harrison PJ. The hippocampus in schizophrenia: a review of the neuropathological evidence and its pathophysiological implications. Psychopharmacology 174:151-162, 2004.

47. Dalman C, Allebeck P, Cullberg J, Grunewald C, Koster M. Obstetric complications and the risk of schizophrenia: a longitudinal study of a national birth cohort. Arch Gen Psychiatry 56: 234-240, 1999.

48. McCarley RW, Wible CG, Frumin M, Hirayasu Y, Levitt J, Fischer IA, Shenton ME. MRI anatomy of schizophrenia. Biol Psychiatry 45:1099-1119, 1999.

49. Chakos MH, Lieberman JA, Alvir J, Bilder RM, Ashtari M. Caudate nuclei volumes in schizophrenic patients treated with typical antipsychotics or clozapine. Lancet 345:456-457, 1995.

50. Lang DJ, Kopala LC, Vandorpe RA, Rui Q, Smith GN, Goghari VM, Lapointe JS, Honer HG. Reduced basal ganglia volumes after switching to olanzapine in chronically treated patients with schizophrenia. Am J Psychiatry 161:1829-1836, 2004.

51. Abi-Dargham A, Gil R, Krystal J, Baldwin RM, Seibyl JP, Bowers $\mathrm{M}$, van Dyke CH, Charney DS, Innis RB, Laruelle M. Increased striatal dopamine transmission in schizophrenia: confirmation in a second cohort. Am J Psychiatry 155:761-767, 1998.

52. Abi-Dargham A, Rodenhiser J, Printz D, Zea-Ponce Y, Gil R, Kegeles LS, Weiss R, Cooper TB, Mann JJ, Van Heertum RL, Gorman JM, Laruelle M. Increased baseline occupancy of D2 receptors by dopamine in schizophrenia. Proc Natl Acad Sci USA 997:8104-8109, 2000.

53. Laruelle M, Abi-Dargham A, Gil R, Kegeles LS, Innis R. Increased dopamine transmission in schizophrenia: relationship to illness phase. Biol Psychiatry 46:56-72, 1999.

54. Laruelle M, Abi-Dargham A, van Dyke CH, Gil R, D'Souza CD, Erdos J, McCance E, Rosenblatt W, Finado C, Zoghbi SS, Baldwin RM, Seibyl JP, Krystal JH, Charney DS, Innis RB. Single photon emission computerized tomography imaging of amphetamine-induced dopamine release in drug-free schizophrenic subjects. Proc Natl Acad Sci USA 93:9235-9240, 1996.

55. Deicken RF, Feiwell R, Schuff N, Soher B. Evidence for altered vermis neuronal integrity in schizophrenia. Psychiatry Res 107: 125-134, 2001. 
56. Ende G, Hubrich P, Walter S, Weber-Fahr W, Kammerer N, Brauss DF, Henn FA. Further evidence for altered cerebellar neuronal integrity in schizophrenia. Am J Psychiatry 162:790792, 2005.

57. Levitt JJ, McCarley RW, Nestor PG, Petrescu C, Donnino R, Hirayasu Y, Kikinis R, Jolesz FA, Shenton ME. Quantitative volumetric MRI study of the cerebellum and vermis in schizophrenia: clinical and cognitive correlates. Am J Psychiatry 156: 1105-1107, 1999.

58. Badner JA, Gershon ES. Metaanalysis of whole-genome linkage scans of bipolar disorder and schizophrenia. Mol Psychiatry 7:405-411, 2002.

59. Lewis CM, Levinson DF, Wise LH, DeLisi LE, Straub RE, Hovatta I, Williams NM, et al. Genome scan meta-analysis of schizophrenia and bipolar disorder. Part II: schizophrenia. Am J Hum Genet 73:34-48, 2003.

60. Stefansson H, Sigurdsson E, Steinthorsdottir V, Bjornsdottir S, Sigmundsson T, Ghosh S, et al. Neuregulin 1 and susceptibility to schizophrenia. Am J Hum Genet 7:877-892, 2002.

61. Stefansson H, Sarginson J, Kong A, Yates P, Steinthorsdottir V, Gudfinnsson E, et al. Association of neuregulin 1 with schizophrenia confirmed in a Scottish population. Am J Hum Genet 72:83-87, 2003.

62. Straub RE, Jiang Y, MacLean CJ, Ma Y, Webb BT, Myakishev $\mathrm{MV}$, et al. Genetic variation in the $6 \mathrm{p} 22.3$ gene DTNBP1, the human ortholog of the mouse dysbindin gene, is associated with schizophrenia. Am J Hum Genet 71:337-348, 2002.

63. Schwab SG, Knapp M, Mondabon S, Hallmayer J, BorrmannHassenbach M, Albus M, et al. Support for association of schizophrenia with genetic variation in the 6 p22.3 gene, dysbindin, in sib-pair families with linkage and in an additional sample of triad families. Am J Hum Genet 72:185-190, 2003.

64. Chumakov I, Blumenfeld M, Guerassimenko O, Cavarec L, Palicio M, Abderrahim $\mathrm{H}$, et al. Genetic and physiological data implicating the new human gene G72 and the gene for D-amino acid oxidase in schizophrenia. Proc Natl Acad Sci USA 99:13675-13680, 2002.

65. Chowdari KV, Mirnics K, Semwal P, Wood J, Lawrence E, Bhatia T, et al. Association and linkage analyses of RGS4 polymorphisms in schizophrenia. Hum Mol Genet 11:1373-1380, 2002.

66. Mirnics K, Middleton FA, Lewis DA, Levitt P. Delineating novel signature patterns of altered gene expression in schizophrenia using gene microarrays. Sci World J 1:114-116, 2001.

67. Shifman S, Bronstein M, Sternfeld M, Pisante-Shalom A, LevLehman E, Weizman A, et al. A highly significant association between a COMT haplotype and schizophrenia. Am J Hum Genet 71:1296-1302, 2002.

68. Egan MF, Goldberg TE, Kolachana BS, Callicott JH, Mazzanti CM, Straub RE, et al. Effect of COMT Val108/158 Met genotype on frontal lobe function and risk for schizophrenia. Proc Natl Acad Sci USA 98:6917-6922, 2001.

69. Liu H, Heath SC, Sobin C, Roos JL, Galke BL, Blundell ML, et al. Genetic variation at the 22q11 PRODH2/DGCR6 locus presents an unusual pattern and increases susceptibility to schizophrenia. Proc Natl Acad Sci USA 99:3717-3722, 2002.

70. Gershon ES, Badner JA. Incorporation of molecular data and redefinition of phenotype: new approaches to genetic epidemiology of bipolar manic depressive illness and schizophrenia. Dialogues Clin Neurosci 3:63-71, 2001.

71. Weinberger DR. Biological phenotypes and genetic research in schizophrenia. World Psychiatry 1:2-6, 2002.

72. Holzman PS. Behavioral markers of schizophrenia useful for genetic studies. Psychiatry Res 26:427-445, 1992.

73. Levy DL, Holzman PS, Matthysse S, Mendell NR. Eye tracking and schizophrenia: a selective review. Schizophr Bull 20:47-62, 1994.

74. McDowell JE, Brenner CA, Myles-Worsley M, Coon H, Byerley W, Clements B. Ocular motor delayed-response task performance among patients with schizophrenia and their biological relatives. Psychophysiology 38:153-156, 2001.
75. Adler LE, Oliney A, Waldo M, Harris JG, Griffith J, Stevens K, et al. Schizophrenia, sensory gating, and nicotinic receptors. Schizophr Bull 24:189-202, 1998.

76. Freedman R, Adler LE, Leonard S. Alternative phenotypes for the complex genetics of schizophrenia. Biol Psychiatry 45:551-558, 1999.

77. Freedman D, Squires-Wheeler E. Event-related potentials (ERP) as an indicator for schizophrenia. Schizophr Bull 20:63-74, 1994

78. Tsuang MT, Stone WS, Faraone SV. Understanding predisposition to schizophrenia: toward intervention and prevention Can J Psychiatry 47:518-526, 2002.

79. Arolt V, Lencer R, Nolte A, Muller-Myhsok B, Purman S, Schurman $M$, et al. Eye tracking dysfunction is a putative phenotypic susceptibility marker of schizophrenia and maps to a locus on chromosome $6 \mathrm{p}$ in families with multiple occurrence of the disease Am J Med Genet 67:564-569, 1996

80. Freedman R, Coon H, Myles-Worsley M, Orr-Urtrager A, Olincy A, Davis A, et al. Linkage of a neurophysiological deficit in schizophrenia to a chromosome 15 locus. Proc Natl Acad Sci USA 94:587-592, 1997.

81. Leonard S, Gault J, Moore T, Hopkins J, Robinson M, Olincy A, et al. Further investigation of a chromosome 15 locus in schizophrenia: analysis of affected sibpairs from the NIMH Genetics Initiative. Am J Med Genet 81:308-312, 1998.

82. Faraone SV, Seidman LJ, Kremen WS, Toomey R, Pepple JR, Tsuang MT. Neuropsychological functioning among the nonpsychotic relatives of schizophrenic patients: a 4-year follow-up study. J Abnorm Psychology 108:176-181, 1999.

83. Hariri AR, Weinberger DR. Imaging genomics. Br Med Bull 65:259-270, 2003.

84. Delay J, Deniker P, Harl JM [Therapeutic use in psychiatry of phenothiazine of central elective action]. Ann Med Psychol 110: 112-117, 1952.

85. Carlsson A, Lindquist M. Effect of chlorpromazine and haloperidol on formation of 3-methoxytyramine and normetanephrine in mouse brain. Acta Pharmacol Toxicol (Copenh) 20:140-144, 1963.

86. Creese I, Burt DR, Snyder SH. Dopamine receptor binding predicts clinical and pharmacological potencies of antischizophrenic drugs. Science 192:481-483, 1976.

87. Seeman P, Lee T, Chau-Wong M. Antipsychotic drug doses and neuroleptic/dopamine receptors. Nature 261:717-719, 1976.

88. Lehmann HE, Ban TA. The history of psychopharmacology of schizophrenia. Can J Psychiatry 42:152-162, 1997.

89. Kane J, Honigfeld G, Singer J, Meltzer H. Clozapine for the treatment-resistant schizophrenic. Arch Gen Psychiatry 45:789296, 1988.

90. Meltzer HY, Alphs L, Green AI, Altamura C, Anand R, Bertoldi AB, Chouinard G, Islam Z, Kane J, Krishnan R, Lindenmayer J-P, Potkin S; International Suicide Prevention Trial Group. Clozapine treatment for suicidality in schizophrenia. Arch Gen Psychiatry 60:82-91, 2003.

91. Naber D, Lambert M. Aripiprazole: a new atypical antipsychotic with a different pharmacological mechanism. Prog Neuro-Psychopharmacol Biol Psychiatry 28:1213-1219, 2004.

92. Davies MA, Sheffler DJ, Roth BL. Aripiprazole: a novel atypical antipsychotic drug with a uniquely robust pharmacology. CNS Drug Rev 10:317-336, 2004.

93. Bolonna AA, Kerwin RW. Partial agonism and schizophrenia. Br J Psychiatry 186:7-10, 2005.

94. Lahti AC, Weiler MA, Corey PK, Lahti RA, Carlsson CA, Tamminga CA. Antipsychotic properties of the partial dopamine agonist (-)-3-(3-hydroxyphenyl)-N-n-propylpiperidine (preclamol) in schizophrenia. Biol Psychiatry 43:2-11, 1998.

95. Coyle JT, Tsai G. The NMDA receptor glycine modulatory site: a therapeutic target for improving cognition and reducing negative symptoms, Psychopharmacology 174:32-38, 2004.

96. Millan MJ. N-methyl-D-aspartate receptors as a target for improved antipsychotic agents: novel insights and clinical perspectives. Psychopharmacology 179:30-53, 2005.

97. Coyle JT, Tsai G, Goff DC. Ionotropic glutamate receptors as therapeutic targets in schizophrenia. Curr Drug Target CNS Neurol Disord 1:183-189, 2002. 
98. Tuominen HJ, Tiihonen J, Wahlbeck K. Glutamatergic drugs for schizophrenia: a systematic review and meta-analysis. Schizophr Res 72:225-234, 2005.

99. Duncan EJ, Szilagyi S, Schwartz MP, Bugarski-Kirola D, Kunzova A, Negi S, Stephanides M, Efferen TR, Angrist B, Peselow E, Corwin J, Gonzenbach S, Rotrosen JP. Effects of D-cycloserine on negative symptoms in schizophrenia. Schizophr Res 71:239-248, 2004.

100. Carpenter WT, Buchanan RW, Javitt DC, Marder SR, Schooler NR, Heresco-Levy U, Gold JM. Is glutamatergic therapy efficacious in schizophrenia. Neuropsychopharmacology 29 [Suppl 1]:S110, 2004.

101. Kehne JH, Baron BM, Carr AA, Chaney SR, Elands J, Feldman DJ, Frank RA, Van Giersbergen PLM, McCloskey TC, Johnson MP, McCarty DR, Poirot M, Senyah Y, Siegel BW, Widmaier C. Preclinical characterization of the potential of the putative atypical antipsychotic MDL 100,907 as a potent $5-\mathrm{HT}_{2 \mathrm{~A}}$ antagonist with a favorable CNS safety profile. J Pharmacol Exp Ther 277:968-981, 1996.

102. Marder SR. Limitations of dopamine-D2 antagonists and the search for novel antipsychotic strategies. Neuropsychopharmacology 21 [Suppl 6]:S117, 1999.

103. Grunder G, Yokoi F, Offord SJ, Ravert HT, Dannals RF, Salzmann JK, Szymanski S, Wilson PD, Howard DR, Wong DF. Time course of $5-\mathrm{HT}_{2 \mathrm{~A}}$ receptor occupancy in the human brain after a single oral dose of the putative antipsychotic drug MDL 100,907 measured by positron emission tomography. Neuropsychopharmacology 17:175-185, 1997.

104. Meltzer HY, Arvanitis L, Bauer D, Rein W; Meta-Trial Study Group. Placebo-controlled evaluation of four novel compounds for the treatment of schizophrenia and schizoaffective disorders. Am J Psychiatry 161:975-984, 2004.

105. Kramer MS, Last B, Getson A, Reines SA; D4 Dopamine Antagonist Group. The effects of a selective D4 dopamine receptor antagonist (L-745,870) in acutely psychotic inpatients with schizophrenia. Arch Gen Psychiatry 54:567-572, 1997.

106. Corrigan MH, Gallen CC, Bonura L, Mechant KM; Sonepiprazole Study Group. Effectiveness of the selective D4 antagonist sonepiprazole in schizophrenia: a placebo-controlled trial. Biol Psychiatry 55:419-445, 2004.

107. Truffinet P, Tamminga CA, Fabre LF, Meltzer HY, Riviere M-E, Papillon-Downey C. Placebo-controlled study of the D4/5-HT2A antagonist fananserin in the treatment of schizophrenia. Am J Psychiatry 156:419-425, 1999.
108. Isaac M, Isaac M, Holloway F. Is cannabis an anti-antipsychotic? The experience in psychiatric intensive care. Hum Psychopharmacol 20:207-210, 2005.

109. Lipska BK. Using animal models to test a neurodevelopmental hypothesis of schizophrenia. J Psychiatry Neurosci 29:282-286, 2004.

110. Beauregard M, Bachevalier J. Neonatal insult to the hippocampal region and schizophrenia: a review and a putative animal model. Can J Psychiatry 41:446-456, 1996.

111. Lipska BK, Jaskiw GE, Weinberger DR. Postpubertal emergence of hyperresponsiveness to stress and to amphetamine after neonatal excitotoxic hippocampal damage: a potential animal model of schizophrenia. Neuropsychopharmacology 9:67-75, 1993.

112. Braff DL, Geyer MA. Sensorimotor gating and schizophrenia. Human and animal model studies. Arch Gen Psychiatry 47:181$188,1990$.

113. Green MF, Nuechterlein KH, Gold JM, Barch DM, Cohen J, Essock S, Fenton WS, Frese F, Goldberg TE, Heaton RK, Keefe RS, Kern RS, Kraemer H, Stover E, Weinberger DR, Zalcman S, Marder SR. Approaching a consensus cognitive battery for clinical trials in schizophrenia: the NIMH-MATRICS conference to select cognitive domains and test criteria. Biol Psychiatry 56: 301-307, 2004.

114. Keefe RSE, Goldberg TE, Harvey PD, Gold JM, Poe MP, Coughenour L. The Brief Assessment of Cognition in Schizophrenia: reliability, sensitivity, and comparison with a standard neurocognitive battery. Schizophr Res 68:283-297, 2004.

115. Pongrac J, Middleton FA, Lewis DA, Levitt P, Mirnics K. Gene expression profiling with DNA microarrays: advancing our understanding of psychiatric disorders. Neurochem Res 27:10491063, 2002.

116. Palfreyman MG, Hook DJ, Klimczak LJ, Brockman JA, Evans DM, Altar CA. Novel directions in antipsychotic target identification using gene arrays. Curr Drug Targets-CNS Neurol Disord 1:227-238, 2002.

117. Kerri S, Janka Z. Critical evaluation of cognitive dysfunctions as endophenotypes of schizophrenia. Acta Psychiatr Scand 110:8391, 2004.

118. Bertolino A, Caforio G, Blasi G, De candia M, Latorre V, Petruzzella V, Altamura M, Nappi G, Papa S, Callicott JH, Mattay VS, Bellomo A, Scarabino T, Weinberger DR, Nardini M. Interaction of COMT (Val(108/158)Met) genotype and olanzapine treatment on prefrontal cortical function in patients with schizophrenia. Am J Psychiatry 161:1798-1805, 2004. 